\title{
Clinical Finding of Electroencephalographic (EEG) Data in Adults: A Retrospective study
}

\author{
Salam A ${ }^{1}$, Banu $\mathrm{SH}^{2}$, Nayeem A ${ }^{3}$, Susan ZS ${ }^{4}$
}

\begin{abstract}
Background: Electroencephalography (EEG) is the first and only real-time monitor of epileptic seizures, and is a powerful measure of cerebral function in the seriously ill. Objective: The purpose of this study was to see the common conditions for doing EEG. Methods: This study was performed retrospectively by collecting and reviewing the electro-clinical information of the adult patients to whom EEGs were done at the 'Central Hospital' laboratory. Clinical problems were categorized into seizures, fainting attacks, headache, giddiness, vertigo, stroke, suicidal tendency, sudden aggressiveness and head injury. Routine EEGs were performed for 30 minutes. EEG findings were categorized as normal for the age, localized or generalized epileptiform discharges, non-epileptogenic dysfunction. Result: In total 53 adult patients 34\% population had fainting attacks, $28 \%$ had seizures, $10 \%$ had stroke and $28 \%$ had complaint related to behavior, suicidal tendency, headache and post head injury problems. EEG was normal in 60\%. Conclusion: EEG is advised for diverse conditions. The proportion of epileptic patients is small, although this is the principal indication for doing routine EEG. [J Shaheed Suhrawardy Med Coll, 2014;6(1):14-17]
\end{abstract}

Keywords: EEG, epilepsy, seizure

Received: March 2014; Revised: April 2014; Accepted: May 2014

\section{Introduction}

Brain cells produce tiny electrical signals known as impulses. EEG helps to measure this electrical activity of the brain ${ }^{1}$. EEG gives functional information of the brain; on the other hand CT scan and MRI give structural information ${ }^{2}$. Although before the advent of Neuro-imaging techniques EEG was done to diagnose various brain abnormalities ${ }^{3}$.

Currently EEG is primarily indicated for the diagnosis and evaluation of the different conditions like epilepsy or any seizure disorder, syncope, non-epileptic attack disorder, infections like Herpes Simplex encephalitis or slow virus diseases and drop attacks. EEG is also performed to evaluate the problems with sleep, to investigate periods of unconsciousness, to monitor the brain during brain surgery and to declare brain death in complicated cases ${ }^{4}$. EEG has relatively low sensitivity in epilepsy, ranging between 25 $56 \%$. Specificity is better; however, it has been varied from 78 to $98 \% \%^{5}$. Misinterpretation of non-epileptogenic phenomena or over interpretation of non-specific EEG abnormalities and spiky paroxysmal variants of normal cerebral rhythms are a common reason for over-diagnosis of epilepsy ${ }^{7}$. Standard

1. Dr. Abdus Salam, Junior Consultant, Department of Neurology, Shaheed Sheikh Abu Naser Specialized Hospital, Khulna

2. Dr. Selina Husna Banu, Associate Professor, Neurosciences Unit, Institute of Child Health and Shishu Shastho Foundation Hospital, Dhaka

3. Dr. Abu Nayeem, Assistant Professor, Department of Neuromedicine, National Institute of Neurosciences \& Hospital, Dhaka

4. Dr. Zobaida Sultana Susan, Junior Consultant, Department of Gynecology \& Obstetrics, Shaheed Suhrawardy Medical College \& Hospital, Dhaka

\section{Correspondence}

Dr. Abdus Salam, Junior Consultant, Department of Neurology, Shaheed Sheikh Abu Naser Specialized Hospital, Khulna, Bangladesh; Email: a.salamk51@gmail.com; Cell no.: +8801712915003

\section{Conflict of interest: None}

Financial Support:This research project was not funded by any group or any institution. There is no external funding.

Contributions by authors: AS: made substantial contributions to conception and design, and acquisition of data, and analysis and interpretation of data; AS, SHB \& AN: participate in drafting the article or revising it critically for important intellectual content; AN \& ZSS: final proofreading and approval of the version for publication. 
activation procedures of hyperventilation up to three minutes and photic stimulation should be included in routine EEG recordings $^{8}$. It is critical to recognize that EEG should be obtained under optimal conditions and the interpretation should be performed by an Epileptologist ${ }^{9}$. There is some limited data to indicate that EEG can be harmful and lead to over diagnosis and unnecessary treatment when used for diagnostic confirmation by less experienced readers. There is a general agreement among epileptologists that over reading is more harmful than under reading and that less experienced readers are more likely to over interpret benign patterns and variants as epileptic. The purpose of this present study was to see the common conditions EEG.

\section{Methodology}

This was a retrospective study carried out in Electrophysiology Laboratory of 'Central Hospital, Dhaka' from July 2011 to June 2012 for a period of one (01) year. Permission was taken from the 'Central Hospital' Authority to use and to analyze the data of their electrophysiology laboratory. The electro-clinical information of the adult patients was collected as well to whom EEG was performed at this laboratory. Presenting problems were categorized, like seizures, fainting attacks, headache, giddiness, vertigo, stroke, suicidal tendency, sudden aggressiveness and head injury. Each recording of EEG was obtained through digital equipments by the EEG machine (Nicolet, USA) with minimal duration of 30 minutes and electrodes were positioned on scalp according to international 10-20 system $^{11}$. The patients with marked artifacts on EEG were excluded from this study. For standardization, the background activity was classified as normal which were organized and also symmetrical or abnormal which were disorganized with or without asymmetry. The EEG was examined for specific epileptiform abnormality, the interictal spike or sharp wave. The abnormal activity was also classified as generalized or focal. The presence and topography of bursts of slow waves and epileptiform paroxysms were evaluated. Again, the epileptiform paroxysms were classified as spike-wave, sharp-wave and poly spike. EEG findings were categorized as normal for the age, localized or generalized epileptiform discharges and non-epileptogenic dysfunction. Statistical analysis was performed by using window based computer software program with Statistical Packages for Social Sciences (SPSS-V.17) (SPSS Inc, Chicago, IL, USA). All data were recorded systematically in preformed data collection form (questionnaire) and quantitative data were expressed as mean and standard deviation and qualitative data were expressed as frequency distribution and percentage. Chi-square test was performed to see the association between qualitative variables.

\section{Results}

A total number of 1466 patients were included in this study of which $53(4.0 \%)$ patients were recruited as study population. Male was 21(40\%) and female was $32(60 \%)$ cases (figure).

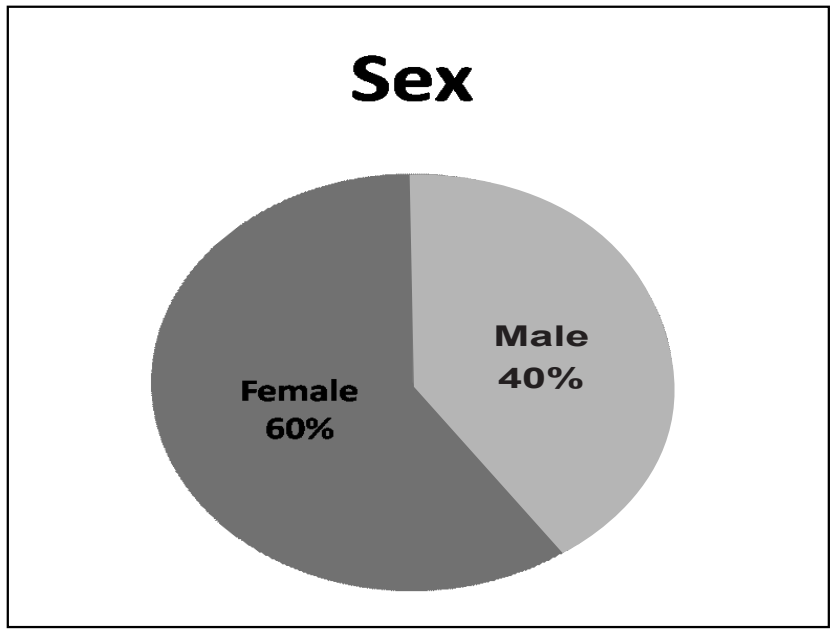

Fig:1- Sex distribution of the study population $(n=53)$

Among the patients $26(48 \%)$ were young ( $>18$ to 30 year), $19(36 \%)$ were in the middle age ( $>30-50$ year), $4(8 \%)$ belong to $50-70$ year age group and $4(8 \%)$ over 70 year age (Table 1$)$.

Table 1: Age distribution of the study population

\begin{tabular}{ccc}
\hline Age group & Number of patients & Percentage \\
\hline$>18-30$ year & 26 & $48 \%$ \\
$>30-50$ year & 19 & $36 \%$ \\
$>50-70$ year & 04 & $08 \%$ \\
$>70$ year & 04 & $08 \%$ \\
\hline
\end{tabular}

The presenting complaints were fainting attacks $18(34 \%)$ patients, seizure $15(28 \%)$ patients, headache $8(15 \%)$ patients, behavioral disturbance $7(13 \%)$ patients and stroke $5(10 \%)$ patients (Table 2).

Table 2: Causes for EEG referral

\begin{tabular}{lcc}
\hline $\begin{array}{c}\text { Causes for EEG } \\
\text { referral }\end{array}$ & $\begin{array}{c}\text { Number of } \\
\text { patients }\end{array}$ & Percentage \\
\hline Seizure & 15 & $28 \%$ \\
Fainting attacks & 18 & $34 \%$ \\
Headache & 08 & $15 \%$ \\
Behavioral & 07 & $13 \%$ \\
disturbance & 05 & 10 \\
Stroke & & \\
\hline
\end{tabular}

EEG was normal in 32(61\%) patients; epileptiform discharge was found in $16(30 \%)$ and nonspecific EEG dysfunction was noted in 5(9\%) patients. Among the patients presenting with history of seizure EEG was found normal in 9(60\%) patients and 6(40\%) patients showed epileptiform abnormality. Among those patients who had complaints other than seizure, 33(87\%) had normal EEG and 5(13\%) showed nonspecific dysfunction. 


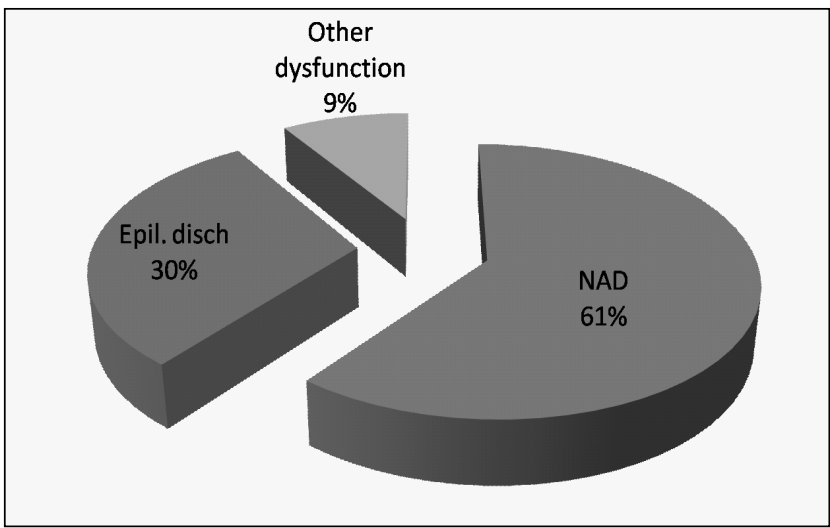

Fig:2- EEG findings of the total population (Epil. Disch= Epileptiform discharge, $\mathrm{NAD}=$ No abnormality detected)

\section{Discussion}

Although the number of study population is small it reflects that reasons for doing an EEG in the adult population are diverse. Only one quarter of the population are referred for the evaluation of seizure disorder which is actually the principal indication. Several published studies on adult epilepsies showed that the chance of detecting interictal epileptiform discharges (IEDs) from the first EEG varies between $29 \%$ and $55 \%$ at outdoor monitoring of patients ${ }^{12-14}$. The present study data also reveals the same scenario. However, in some studies it is evident that EEG may be positive up to $70 \%$ case $^{15}$.

\section{Table 3: EEG Findings of the total population}

\begin{tabular}{lcc}
\hline EEG report & Frequency & Percentage \\
\hline Normal & 32 & $61 \%$ \\
Epileptiform discharge & 16 & $30 \%$ \\
$\begin{array}{l}\text { Other non-specific } \\
\text { dysfunction }\end{array}$ & 05 & $09 \%$ \\
Total & 53 & $100 \%$ \\
\hline
\end{tabular}

Besides any brain pathology like traumatic brain injury, stroke would show some abnormality in EEG. These findings have no practical application unless associated with clinical problems. In this era of neuro-imaging facilities, unnecessary requisition for EEG increases load on the laboratory and provides no extra beneficial information. Major portion of the study population is female who are referred for psychogenic complaints where EEG has no significant role. So selection of the patients for whom EEG is recommended should be based on sound knowledge about seizure and power of EEG to identify various cerebral pathology. More studies are required in other centers to justify the situation.

In specialized units, video-EEG or ambulatory long term EEG monitoring to obtain an ictal recording are very helpful, but these techniques are not available in most cases $^{16}$. It is therefore not surprising that epilepsy frequently is misdiagnosed in children and even in adult. Many paroxysmal events may be mistaken for epilepsy like tics, staring, syncope, dystonia, psychogenic seizures, and behavioural disturbances during sleep ${ }^{17}$.
Table 4: EEG Finding according to clinical problem

\begin{tabular}{lccc}
\hline EEG Finding & \multicolumn{2}{c}{ Clinical Problems } & \multirow{2}{*}{ Total } \\
\cline { 2 - 3 } & $\begin{array}{c}\text { Seizure } \\
\text { patients }\end{array}$ & $\begin{array}{c}\text { Non-seizure } \\
\text { patients }\end{array}$ \\
\hline Normal & $9(60.0 \%)$ & $33(87.0 \%)$ & $42(79.2 \%)$ \\
Abnormal & $6(40.0 \%)$ & $5(13.0 \%)$ & $11(20.8 \%)$ \\
Total & $\mathbf{1 5 ( 1 0 0 . 0 \% )}$ & $\mathbf{3 8 ( 1 0 0 . 0 \% )}$ & $\mathbf{5 3 ( 1 0 0 . 0 \% )}$ \\
\hline
\end{tabular}

*Chi-square test has been performed (3.221); p-value: 0.073

\section{Conclusion}

In conclusion, it is very clear that in majority cases EEG is performed to diagnose epilepsy. In addition to that EEG is done among the younger age group of femele patient. Fur thes more. Seizures \& fainting altacks are the most commouns symptoms where EEG is investigated.

\section{References}

1. Trescher WH, Lesser RP. The Epilepsies. In: Bradley WG, Daroff RB, Fenichel GM, Jankovic J, eds. Neurology in Clinical Practice. 5th ed. Philadelphia, Pa: Butterworth-Heinemann; 2008

2. Niedermeyer EDS, Fernando L; Electroencephalography, 5th ed. 2005, Lippincott Williams \& Wilkins

3. Aliberti V, Granewald RA, Panayiotopoulos CP, Chroni E. Focal electroencephalographic abnormalities in juvenile myoclonic epilepsy. Epilepsia. 1994;35(2):297-301

4. Niedermeyer E, da Silva FHL. Electroencephalography: basic principles, clinical applications, and related fields: Lippincott Williams \& Wilkins, 2005

5. Pivik RT, Broughton RJ, Coppola R, Davidson RJ, Fox N, Nuwer MR. Guidelines for the recording and quantitative analysis of electroencephalographic activity in research contexts. Psychophysiology. 1993;30(6):547-58

6. Benbadis SR, Tatum WO. Overintepretation of EEGs and misdiagnosis of epilepsy. Journal of clinical neurophysiology. 2003;20(1):42-4

7. Binnie CD. Epilepsy in adults: diagnostic EEG investigation. In: Kimura J, Shibasaki H, eds. Recent advances in clinical neurophysiology. Amsterdam: Elsevier, 1996:217-22

8. Benbadis SR, Lin K. Errors in EEG interpretation and misdiagnosis of epilepsy. European neurology. 2008;59(5):267-71

9. Smith SJM. EEG in the diagnosis, classification, and management of patients with epilepsy. Journal of Neurology, Neurosurgery \& Psychiatry. 2005;76(suppl 2):ii2-ii7

10. NICE The epilepsies: diagnosis and management of the epilepsies in children and young people in primary and secondary care. National Institute for Clinical Excellence (NICE) Clinical Guideline 20, October, 2004

11. Flink R, Pedersen B, Guekht AB, Malmgren K, Michelucci R, Neville $\mathrm{B}$, et al. Guidelines for the use of EEG methodology in the diagnosis of epilepsy. Acta Neurologica Scandinavica. 2002;106(1):1-7

12. Marsan CA, Zivin LS. Factors related to the occurrence of typical paroxysmal abnormalities in the EEG records of epileptic patients. Epilepsia. 1970;11(4):361-81

13. Goodin DS, Aminoff MJ, Laxer KD. Detection of epileptiform activity by different noninvasive EEG methods in complex partial epilepsy. Annals of neurology. 1990;27(3):330-4

14. Salinsky M, Kanter R, Dasheiff RM. Effectiveness of multiple EEGs in supporting the diagnosis of epilepsy: an operational curve. Epilepsia. 1987;28(4):331-4

15. Schreiner A, Pohlmann-Eden B. Value of the early electroencephalogram 
after a first unprovoked seizure. Clinical EEG 2003;34(3):140-4 16. Uldall P, Alving J, Hansen LK, Kibak M, Buchholt J. The misdiagnosis of epilepsy in children admitted to a tertiary epilepsy centre with paroxysmal events. Archives of disease in childhood. 2006;91(3):219-21

17. Paolicchi JM. The spectrum of non-epileptic events in children. Epilepsia 2002;43(suppl 3):60-4 